\title{
Evaluation of Irrigation Scheduling Strategies on Partial Nutrient Balance for Tomato Production at Bechet Watershed, Abbay Basin, Ethiopia
}

\author{
Natnael Yasab Assefa \\ Debre Markos Institute of Technology, School of civil and water resources engineering \\ Academic program of Hydraulic and Water Resources Engineering
}

\begin{abstract}
Reasonable and efficient utilization of the water and soil resources are viable so as to maximize the production and productivity of the farm land. Unwise utilization of those two most critical resources results on the decline of production and productivity. Managing irrigation water delivered to the irrigation field could able to increase the yield by controlling the nutrient flow system in the soil media. The objective of this study is to evaluate the different water management methods on yield maximization by providing a great attention to the partial nutrient balance system. The study have a brief on the quantification of irrigation water required to a given plot by following technical approach of continues soil moisture measurement using sensor device Time Domain reflect meter (TDR) and through the use of 10 years back climatic historical data from Bahir Dar weather station data. The usual farmers practice have become evaluated and compared with the technical management methods in terms of water demand at each plot and partial nutrient balance pattern. To achieve the comparison, the experimental plots were prepared and grouped in to the three categories. The comparison result shows that usual farmers practice have used more water for some plots and less water for some plots not matching exactly on the requirement level of the crop; less crop yield and more positive partial $\mathrm{N}$ balance and negative $\mathrm{P}$ and $\mathrm{K}$ balance other than the technical management methods. The average partial Nitrogen (N)depletion balance for TDR, CWR,FARM were, $-90.6 \mathrm{~kg} / \mathrm{ha},-151.3 \mathrm{~kg} / \mathrm{ha}$ and $18.8 \mathrm{~kg} / \mathrm{ha}$; Phosphorus (P) depletion balance were $-0.6 \mathrm{~kg} / \mathrm{ha},-0.5 \mathrm{~kg} / \mathrm{ha}$, and $-0.2 \mathrm{~kg} / \mathrm{ha}$ and potassium $(\mathrm{K})$ depletion balance were; $-284 \mathrm{~kg} / \mathrm{ha},-270 \mathrm{~kg} / \mathrm{ha}$ and $-97.2 \mathrm{~kg} / \mathrm{ha}$ respectively. The Average crop yield was $33.2 \mathrm{Mg}$ ha-1; $31.67 \mathrm{Mg}$ ha-1; $20.8 \mathrm{Mg}$ ha-1 for CWR; TDR; and FARM water management groups respectively. The respective average water consumption of CWR, TDR and FARM were $590 \mathrm{~mm}, 476 \mathrm{~mm}$ and $575 \mathrm{~mm}$ respectively. Keywords: TDR, WFD, CWR, FARM, Nitrogen, phosphorus, potassium.
\end{abstract}

DOI: $10.7176 / \mathrm{CER} / 12-10-04$

Publication date:October $31^{\text {st }} 2020$

\section{Introduction}

The Ethiopian farming system depends strongly on rainfed smallholder farm as a means of food and income for its population; virtually all food crops come from rainfed agriculture system (Hordofa et al., 2008). Rainfed agriculture products are not sufficient to ensure food security and market demand of the society. Irrigated agriculture is as crucial as it does not only to provide resilience under variable climatic conditions but also to provide agricultural products outside of the main cropping season, ensuring availability of products throughout the year.

Irrigated agriculture uses surface water or groundwater to ensure crop production outside of the rainy season or, when supplementary, improves resilience during the rainy season. Systematic application of irrigation water is crucial to ensure efficient utilization of water and other resources (Etissa et al., 2014b). Irrigation application plays a vital role in the water and crop productivity, safe nutrient movement in the soil and sustainable use of land resources (Awulachew et al., 2005, Ali and Talukder, 2008).

For a specific crop, the crop water requirement during its various growth stages is different, and influenced by the weather conditions as it influences the rate of water movement from both the plant (i.e. transpiration) and the soil (i.e. evaporation). The efficient use of water is also dependent upon the relationship of both deficiencies and excesses of water to plant growth (Ali and Talukder, 2008). Efficient water usage must be based upon a thorough understanding of climatic, soil, crop and management factors. Climate is uncontrolled but it is possible to modify its effects through good irrigation and crop management. The practical questions are therefore: what are the effects of over-watering, how much water should be used, and what is the proper rate of watering?" (Wheater and Evans, 2009). Excess irrigation can lead to permanent loss of land resources and leaching out of nutrients through lateral flow and deep percolation. Water as well as nutrients are lost within the system leading to severe on-site (e.g. decreasing soil fertility, soil compaction) and off-site effects (e.g. eutrophication of water bodies)

Farming in Ethiopian strongly depends on rain fed smallholder as a means of food and income for its population; virtually all food crops come from rain fed agriculture system (Hordofa et al., 2008). Irrigation requirement is unquestionable and it is on a good start but, the critical thing is management of the irrigated water. Ethiopian most irrigation practice is furrow based which overuse water and deplete nutrient. 


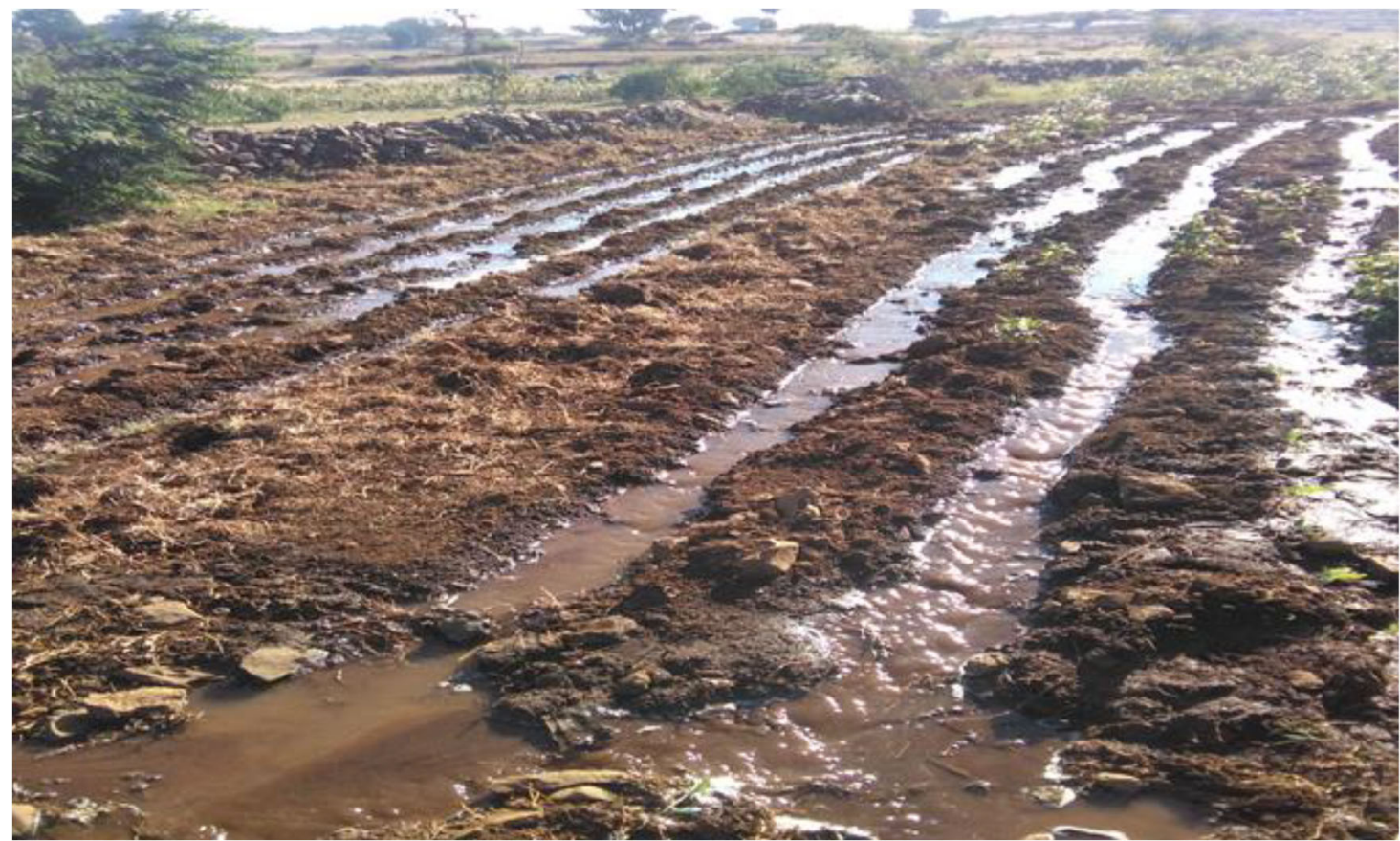

Photo taken by: Natnael Yasab, 2019

\subsection{Problem of statement}

Rainfed agricultural system is the most common production system in Ethiopia. However, given the rising population and climatic variability, the provision of food security is a challenge. Irrigation can aid in ensuring food security during the dry season and improve people livelihoods. However, water is a scarce resource in many parts of the world requiring an efficient and sustainable use both in quality and quantity. In common irrigation practices the irrigation water is applied over the irrigable area without considering the amount needed and time of the requirement by plant. The scheduling and application of irrigation water as well as fertilizer is used whenever the farmer is able to access water or has the means to buy fertilizer and does not necessarily follow the crop requirement (Gebreselassie, 2003). Little is known in Ethiopia on the optimal irrigation requirement for small holder farms using manual water lifting technologies for the cultivation and irrigation of high value crops such as vegetables. Furthermore, the effect of irrigation practices and different irrigation scheduling methods on soil nutrient balances (N, P and K) are poorly understood within this context. The practice of farmer's irrigation application is most of the time either more or less than the crop water requirement.

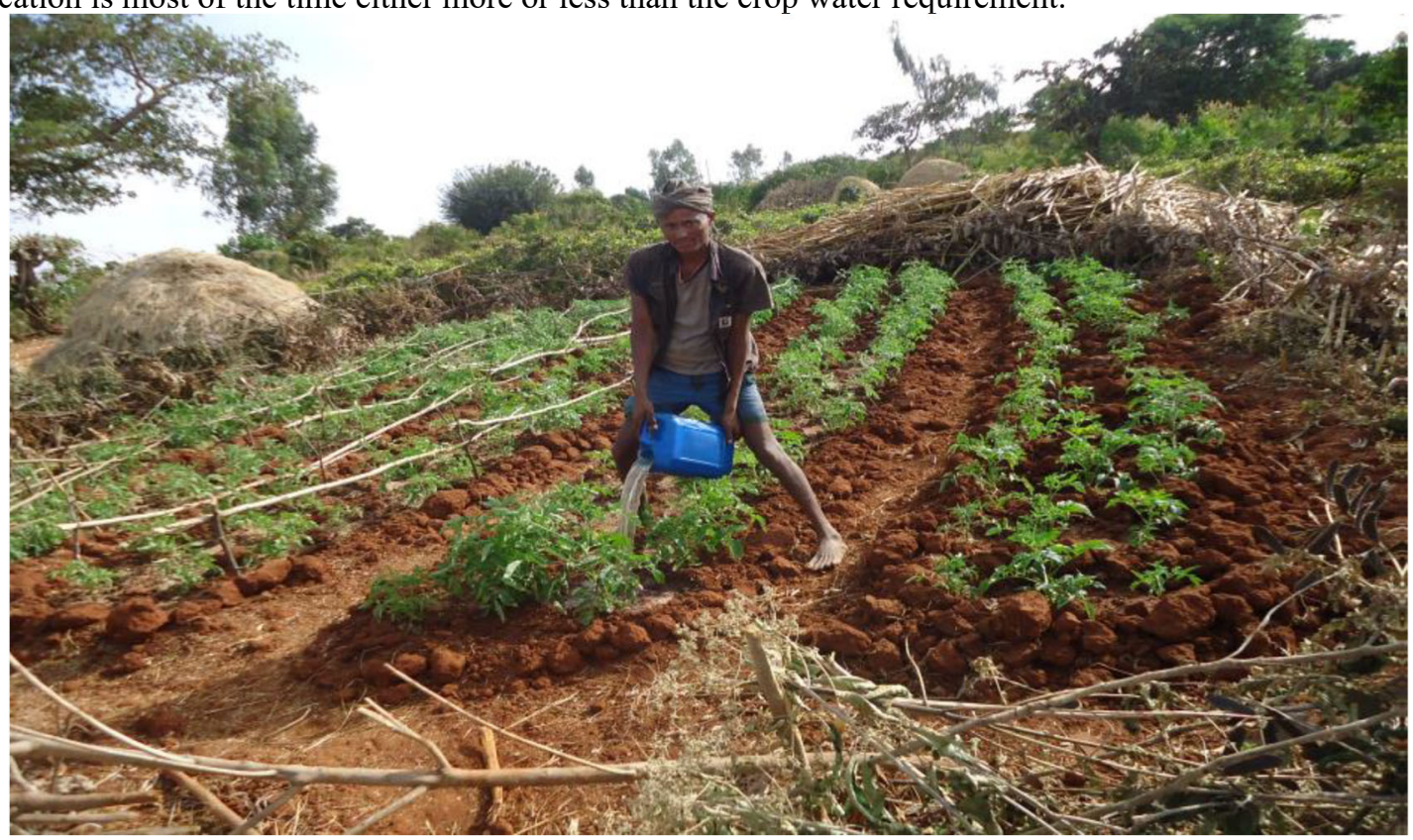

Photo taken by: Natnael Yasab, 2016

There are Studies in relation to water management based on different tools but potentially not linked with 


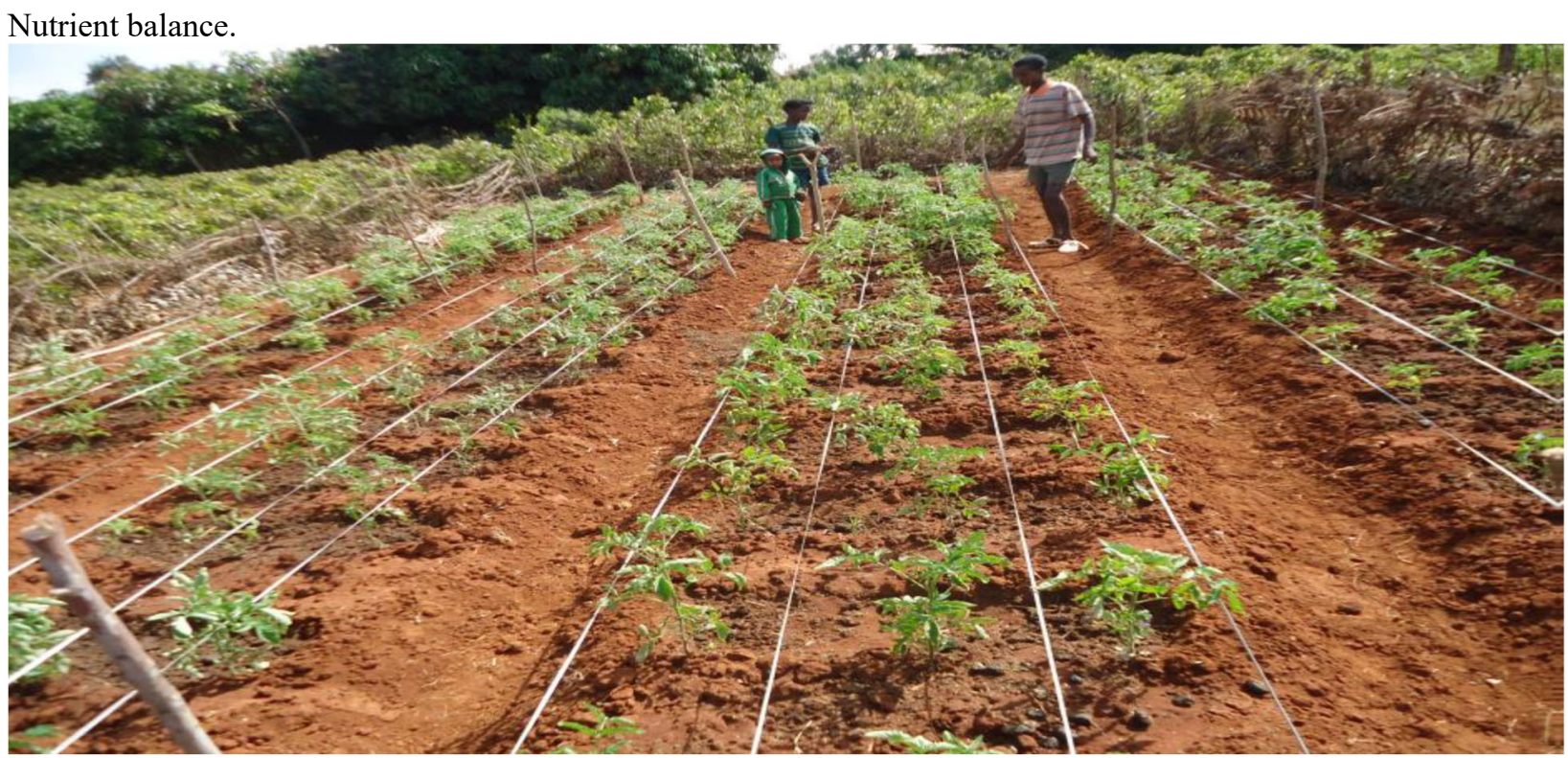

Photo taken by: Natnael Yasab, 2016

\subsection{Objective of the study}

1.2.1. General objective

To investigate the role of irrigation scheduling on crop and water productivity and partial nutrient balances (i.e. N, $\mathrm{P}$ and $\mathrm{K})$ for tomato in the dry season.

\subsubsection{Specific objective}

a) To compare three irrigation water management methods (Farmers' practice, soil moisture based scheduling and crop water requirement scheduling)

b) To compare differences in crop and water productivity for three different irrigation methods

c) To investigate the impact of three irrigation methods on partial nutrient balances.

\section{Data collection and methods}

\subsection{Description of study area}

The study area was situated within the Bechet watershed. Soil type: Nitisols- (Cay/clay loam. (tex) ,Rainfed crops:(Maize, wheat, teff), Irrigated crops:(onion, vegetables, fruits) and Water source for irrigation:(SW \& Gw).

\subsection{Methods of the study}

\subsection{1 . Experimental Design}

24 farmers were grouped in to three treatments based on their

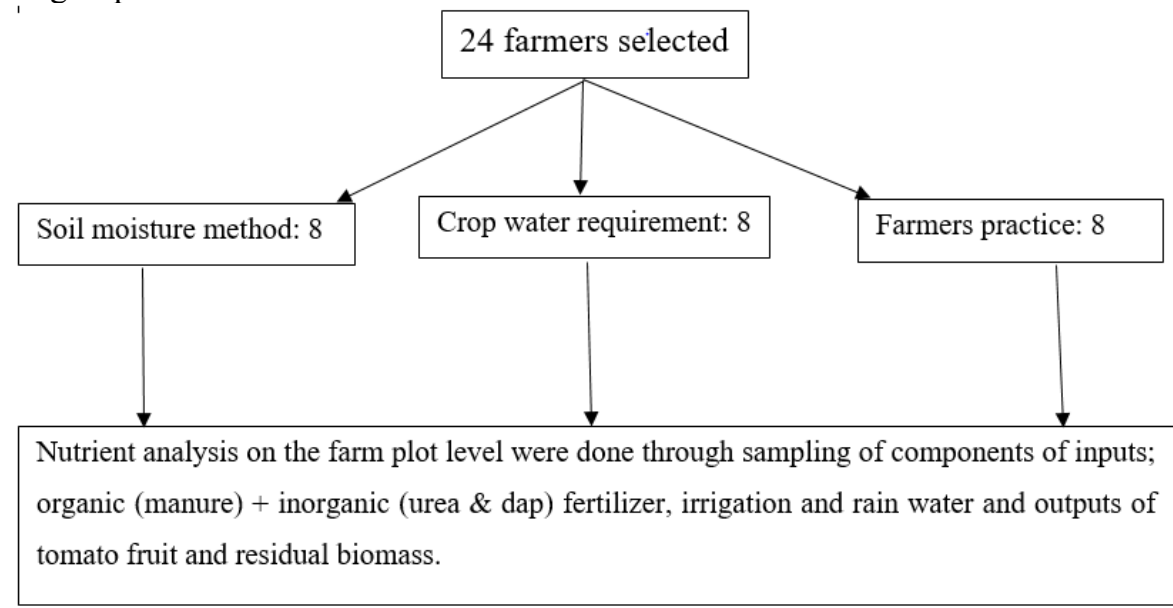

Figure 2.1: flow chart for the overall activities delivered and ways for the experiment design

\subsubsection{Data collection}

Historical 13 years weather data From BDR, (2005-2018) as well as irrigation season for 2019. Automatic Tipping bucket, for rainfall Data at time of irrigation. Fertilizer quantity and quality, Irrigation quantity and quality, Rainfall 
quantity and quality, Biomass and yield produced quantity and quality; were measured and analyzed.

Partial nutrient balance (N, P and $\mathrm{K})$ :

$I N 1+I N_{2}+I N_{3}=O U T_{1}+O U T_{2}$

Organic and inorganic fertilizer

- Atmospheric wet deposition

- Irrigation water

- Harvested yield

- Crop residue

- No leaching was there

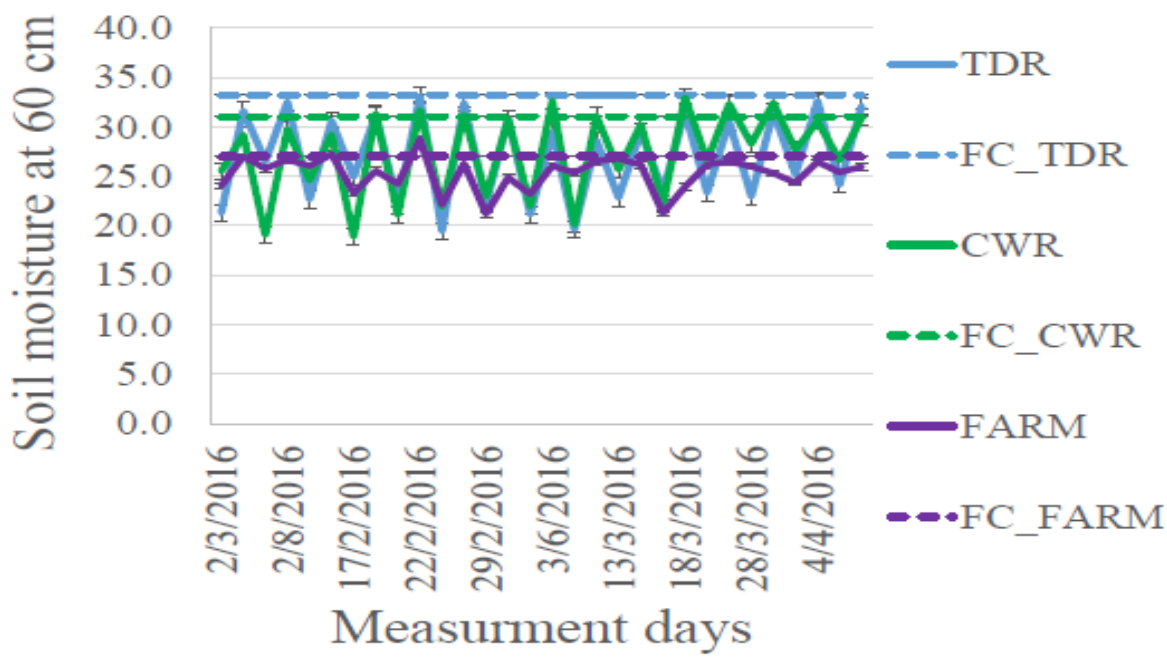

Figure 2.1: the average soil moisture at $60 \mathrm{~cm}$ depth for the three treatments with respective average Field capacity.

\section{Result of the study}

\subsection{Soil physicochemical properties before tomato transplanting}

In this study soil samples from 24 experimental plots (i.e. 8 plots per treatment) were analyzed.

Soil $\mathrm{pH}$ analysis result values within $20 \mathrm{~cm}$ depth were ranging for TDR treatments within 5.9- 6.4, CWR treatment's within 5.8-6.3 and control groups within 5.8-6.8 which is equivalent to tomato requirement in terms of $\mathrm{pH}$. Cation exchange capacity of the soil ranges $0.01-0.3,0.1-0.2$ and $0.1-0.3$ for TDR, CWR and FARM treatments respectively which is somewhat less from the standard tomato requirement. Soils with a pH range of 5.5- 6.8 and EC of 1-3 dS m-1, with optimum concentration of available N-P-K, and Fe with a clay loamy texture soils are suitable and have a high yield potential for tomato production in altitudes ranging from 700 to1400 mm. For all other parameters measured, the soils in 3 treatment groups seem suitable for tomato production (Table 3.1). It is observed that some parameters vary strongly within a group. For example organic matter (OM) content for plot PR11T has $6.9 \%$ which is higher compared to other plots (e.g. 1.8 for PR2FR and 2.0 for PR3T - Appendix A). As discussed in section 3.4 higher - lower organic matter was linked to historical land use and fertilizer management. 
Table 3.1: Mean and standard deviation (SD) and coefficient of variation (CV, \%) for the soil physiochemical parameters at $20 \mathrm{~cm}$ depth.

\begin{tabular}{|c|c|c|c|c|c|c|}
\hline \multirow{2}{*}{ Soil Parameters } & \multicolumn{7}{|c|}{ TDR } & \multicolumn{2}{c|}{ CWR } & \multicolumn{2}{c|}{ FARM } \\
\cline { 2 - 7 } & Mean \pm SD & CV \% & Mean \pm SD & CV \% & Mean \pm SD & CV \% \\
\hline PH & $6.2 \pm 0.2$ & 2.9 & $6 \pm 0.2$ & 3.7 & $6.6 \pm 0.4$ & 6.3 \\
\hline EC ds/m & $0.1 \pm 0.1$ & 96.5 & $0.1 \pm 0.1$ & 38.2 & $0.2 \pm 0.1$ & 62.7 \\
\hline CEC \% & $34 \pm 9.7$ & 28.3 & $40 \pm 10.7$ & 26.8 & $42 \pm 7$ & 16.5 \\
\hline OM \% & $4 \pm 1.9$ & 48.4 & $3 \pm 0.8$ & 25.1 & $4.6 \pm 1.8$ & 38.6 \\
\hline TN \% & $0.2 \pm 0.1$ & 48.8 & $0.2 \pm 0.04$ & 23.6 & $0.2 \pm 0.1$ & 38.6 \\
\hline Av. P ppm & $18.4 \pm 12$ & 64.9 & $14.5 \pm 8.8$ & 60.8 & $15.4 \pm 7.4$ & 47.7 \\
\hline Fe \% & $13 \pm 11$ & 84.7 & $8.5 \pm 1.5$ & 18.0 & $14.8 \pm 6$ & 40 \\
\hline FC \% & $33 \pm 4$ & 12.3 & $34 \pm 4.6$ & 13.3 & $37 \pm 5$ & 13.3 \\
\hline PWP \% & $22 \pm 2$ & 7.7 & $21 \pm 1.9$ & 8.9 & $23.7 \pm 2.8$ & 11.9 \\
\hline K ppm & $642 \pm 780$ & 121.5 & $244.7 \pm 125.6$ & 51 & $905 \pm 708$ & 86.3 \\
\hline
\end{tabular}

According to Wei et al.,(2007) soil property variation can be described in terms of coefficient of variation (CV) with $\mathrm{CV}<10 \%$ showing low variability and $\mathrm{CV}>90 \%$ indicating high variability. For the soil samples taken at $20 \mathrm{~cm}, 5$ from each treatments, results showed that the $\mathrm{pH}$ was less varied with in plots in each treatments additionally PWP was less varied with in TDR and CWR treatments. On the other hand K, was highly varied in the TDR treatments. The coefficient of variation was found between $10 \%$ and $90 \%$ which indicates moderate variation for the rest of soil properties within the treatment group. The coefficient of variation for $\mathrm{pH}$ was very low for $20 \mathrm{~cm}$ depth sample (i.e. 2.9 - $6.3 \%$ ) whereas for $\mathrm{K}$ values ranged from moderate $51 \%$ in the CWR to $86.3 \%$ in the FARM and very highly varied in the TDR $121.5 \%$ treatments.

Table 3.2 Mean and standard deviation (SD) and coefficient of variation $(\mathrm{CV}, \%)$ for the soil

Physiochemical parameters at $60 \mathrm{~cm}$ depth

\begin{tabular}{|c|c|c|c|c|c|c|}
\hline \multirow{2}{*}{} & \multicolumn{7}{|c|}{ TDater management groups } & \multicolumn{2}{c|}{ CWR } & \multicolumn{2}{c|}{ CWR } \\
\cline { 2 - 7 } Parameters & Mean \pm SD & CV \% & Mean \pm SD & CV \% & Mean \pm SD & CV \% \\
\hline PH & $6.7 \pm 0.42$ & 6.2 & $5.9 \pm .7$ & 11.6 & $6 \pm 0.6$ & 10.4 \\
\hline EC ds/m & $0.2 \pm 0.14$ & 70.6 & $0.1 \pm 0.1$ & 74.8 & $0.1 \pm 0.1$ & 69.3 \\
\hline CEC \% & $35.4 \pm 9.1$ & 25.7 & $30.7 \pm 4.4$ & 14.4 & $30 \pm 7.2$ & 23.8 \\
\hline OM \% & $3.9 \pm 0.9$ & 23.9 & $3.8 \pm 0.7$ & 19.4 & $3.7 \pm 7.2$ & 193.3 \\
\hline TN \% & $0.2 \pm 0.1$ & 23.9 & $0.2 \pm 0.05$ & 26.5 & $0.2 \pm 0.1$ & 27.0 \\
\hline Av. P ppm & $15 \pm 6.7$ & 44.2 & $27.2 \pm 23.2$ & 85.4 & $9.8 \pm 2.3$ & 29.3 \\
\hline Fe \% & $9.5 \pm 3$ & 31.4 & $9.6 \pm 3.5$ & 36.5 & $6.8 \pm 2.0$ & 28.3 \\
\hline FC \% & $33.2 \pm 5.3$ & 15.9 & $30.8 \pm 2.5$ & 8.2 & $27 \pm 3.8$ & 14.2 \\
\hline PWP \% & $21.8 \pm 2$ & 9.3 & $20.8 \pm 2.3$ & 11.0 & $19 \pm 3.3$ & 17.3 \\
\hline K ppm & $986.8 \pm 926.7$ & 93.9 & $391 \pm 258$ & 66.1 & $518 \pm 532$ & 102.6 \\
\hline
\end{tabular}

A similar analysis for the CV measured at both 20 and $60 \mathrm{~cm}$ depth showed a significant difference between the three treatment groups except for potassium (detailed data and statistical analysis are in Appendices A and T, respectively). The potassium values in the TDR group at $20 \mathrm{~cm}$ and $60 \mathrm{~cm}$ depth were 642 and $986.8 \mathrm{ppm}$ respectively, which were significantly higher than those in the CWR and not significantly from FARM group. This might influence potential differences in tomato growth between the three treatment groups if not replenished by fertilizer. CV of $\mathrm{pH}$ and PWP was less varied for TDR treatment whereas moderately varied for CWR and FARM treatments. 


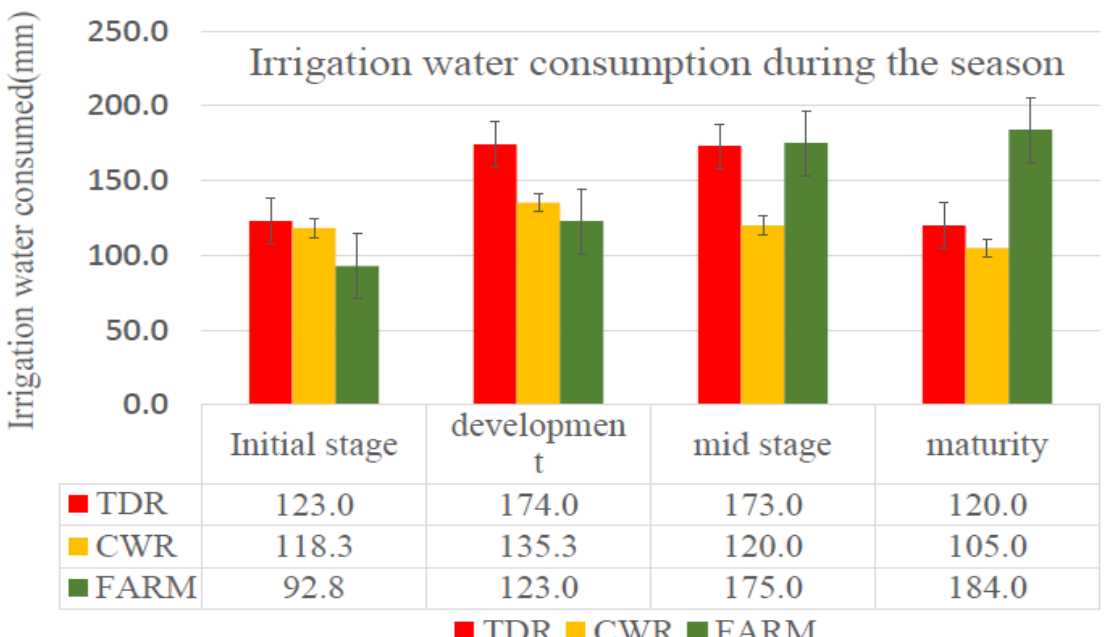

\begin{tabular}{ll}
\hline Treatment & $\begin{array}{l}\text { Irrigation } \\
\text { (mm) }\end{array}$ \\
\hline TDR & 590 \\
CWR & 476 \\
FARM & 575 \\
\hline
\end{tabular}

No significant difference $\mathrm{b} / \mathrm{n}$ treatments

Figure 3.1. Irrigation water consumption during irrigation seasons

3.2. Water productivity and water use efficiency of three Methods.

Table 3.3 shows the water productivity for the three groups using the fresh tomato yield and the details are given in appendix D. The number of observations used for water productivity were 8 for CWR, 6 for TDR and 5 for farmers local practice treatments.

Table 3.3: The average, minimum, maximum and standard deviation (SD) of water productivity and yield for the three management groups (CWR, TDR and FARM).

\begin{tabular}{|c|c|c|c|c|c|c|}
\hline & \multicolumn{2}{|c|}{ CWR } & \multicolumn{2}{c|}{ TDR } & \multicolumn{2}{c|}{ FARM } \\
\hline & $\begin{array}{c}\text { WP } \\
\left(\mathrm{kg} \mathrm{m}^{-3}\right)\end{array}$ & $\begin{array}{c}\text { Yield } \\
\left(\mathrm{kg} \mathrm{ha}^{-1}\right)\end{array}$ & $\begin{array}{c}\text { WP } \\
\left(\mathrm{kg} \mathrm{m}^{-3}\right)\end{array}$ & $\begin{array}{c}\text { Yield } \\
\left(\mathrm{kg} \mathrm{ha}^{-1}\right)\end{array}$ & $\begin{array}{c}\text { WP } \\
\left(\mathrm{kg} \mathrm{m}^{-3}\right)\end{array}$ & $\begin{array}{c}\text { Yield } \\
\left(\mathrm{kg} \mathrm{ha}^{-1}\right)\end{array}$ \\
\hline Min & 3 & 12143 & 1 & 7604 & 1 & 7423 \\
\hline Max & 11 & 48000 & 12 & 67167 & 9 & 42222 \\
\hline Average & $8^{\mathrm{a}}$ & $33203^{\mathrm{a}}$ & $5^{\mathrm{a}}$ & $31675^{\mathrm{a}}$ & $4^{\mathrm{a}}$ & $20843^{\mathrm{b}}$ \\
\hline SD & 3 & 13857 & 4 & 21257 & 3 & 15953 \\
\hline CV \% & 41 & 42 & 30 & 74 & 91 & 73 \\
\hline
\end{tabular}

As shown in Table 3.3 the water productivity ranged between 3 and $11 \mathrm{~kg} \mathrm{~m}^{-3}$ for CWR, 1 and $12 \mathrm{~kg} \mathrm{~m}^{-3}$ for TDR, 1 and $9 \mathrm{~kg} \mathrm{~m}^{-3}$ for FARM. Although, no significant differences are observed between the three irrigation treatments higher values were observed in the TDR group compared to the CWR and the FARM group. Water productivity is the measure of quantity of production per the volume of water consumed for these production. The average value of WP does not show significant different where as the coefficient of variation is medium in the CWR and TDR group treatments whereas the FARM treatments had high coefficient of variation in the water productivity up on the range 10-90\% medium variation rule of( Wei t.al.,2007).

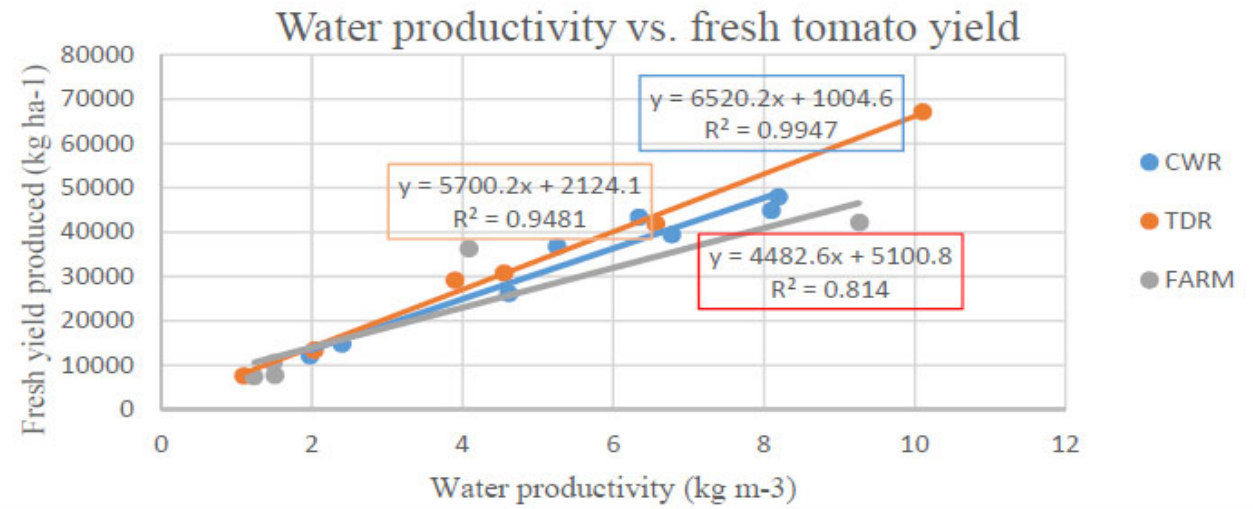

Figure 3.2: Scatter plot of total fresh yield (kg ha-1) observed at plot level. Water productivity $(\mathrm{Kg} \mathrm{m}-3)$ for the three treatment groups. 
3.3. Agronomic performance of tomato

3.3.1. Effect of different fertilizer on yield

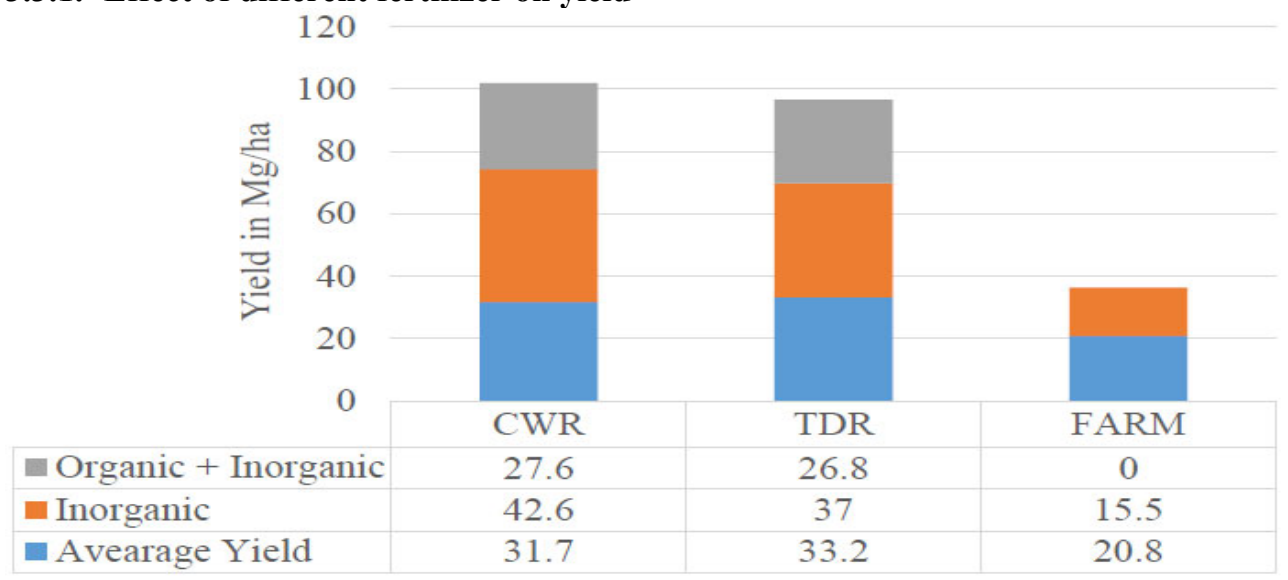

Figure 3.3: effects of fertilizers on the yields

3.3.2. Partial $\mathbf{N}$ balance

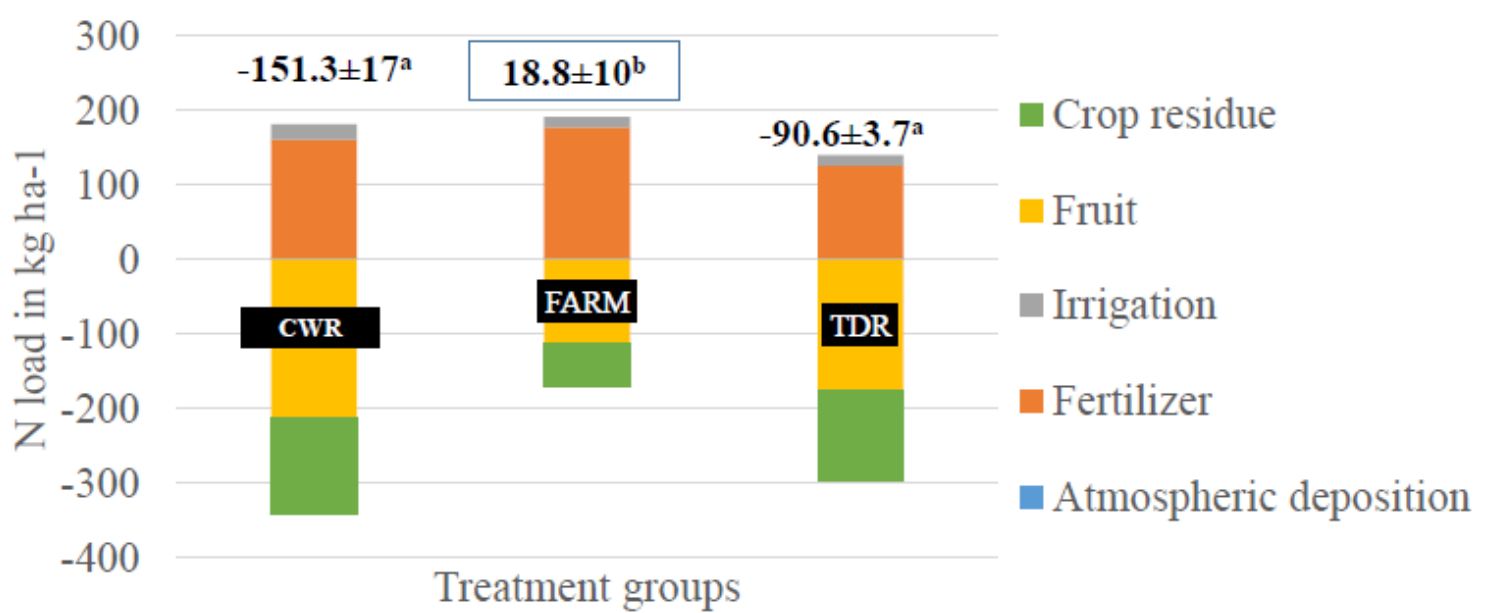

Figure 3.4: Partial depletion balance of $\mathrm{N}$ (kg ha-1) for the three treatment groups when Only mineral fertilizer is used.

\subsubsection{P \& K Partial balance}

- P-load in $\mathrm{kg} / \mathrm{ha}$

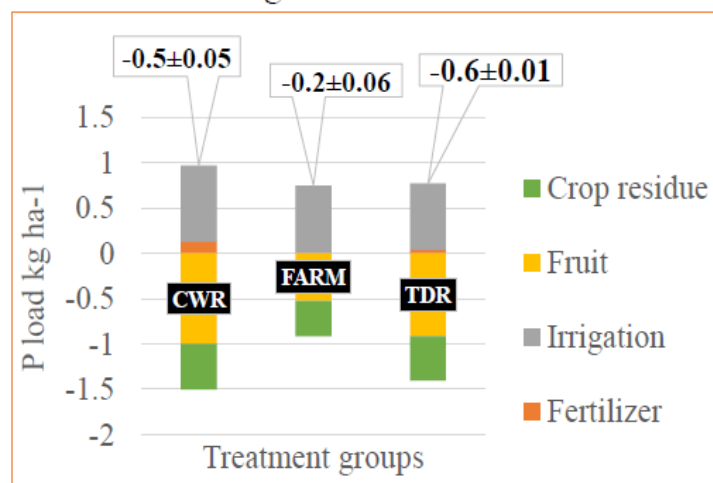

- K-load in $\mathrm{kg} / \mathrm{ha}$

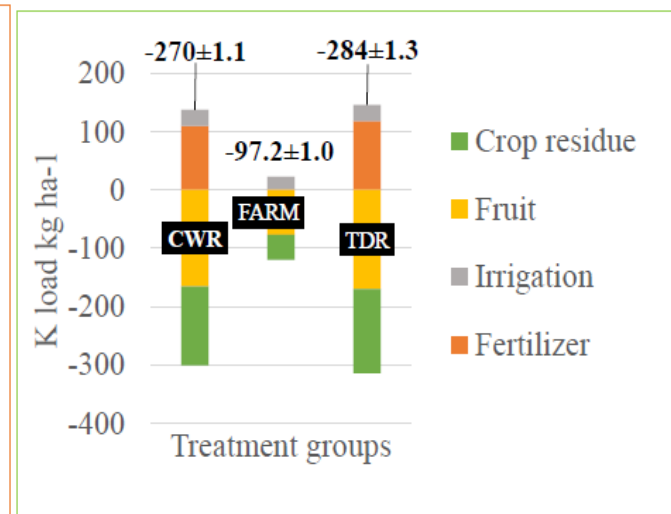

3.5: Partial depletion balance of P- K (kg ha-1) for the three treatment groups when Only mineral fertilizer is used. 


\subsubsection{Partial balance by different fertilizer}

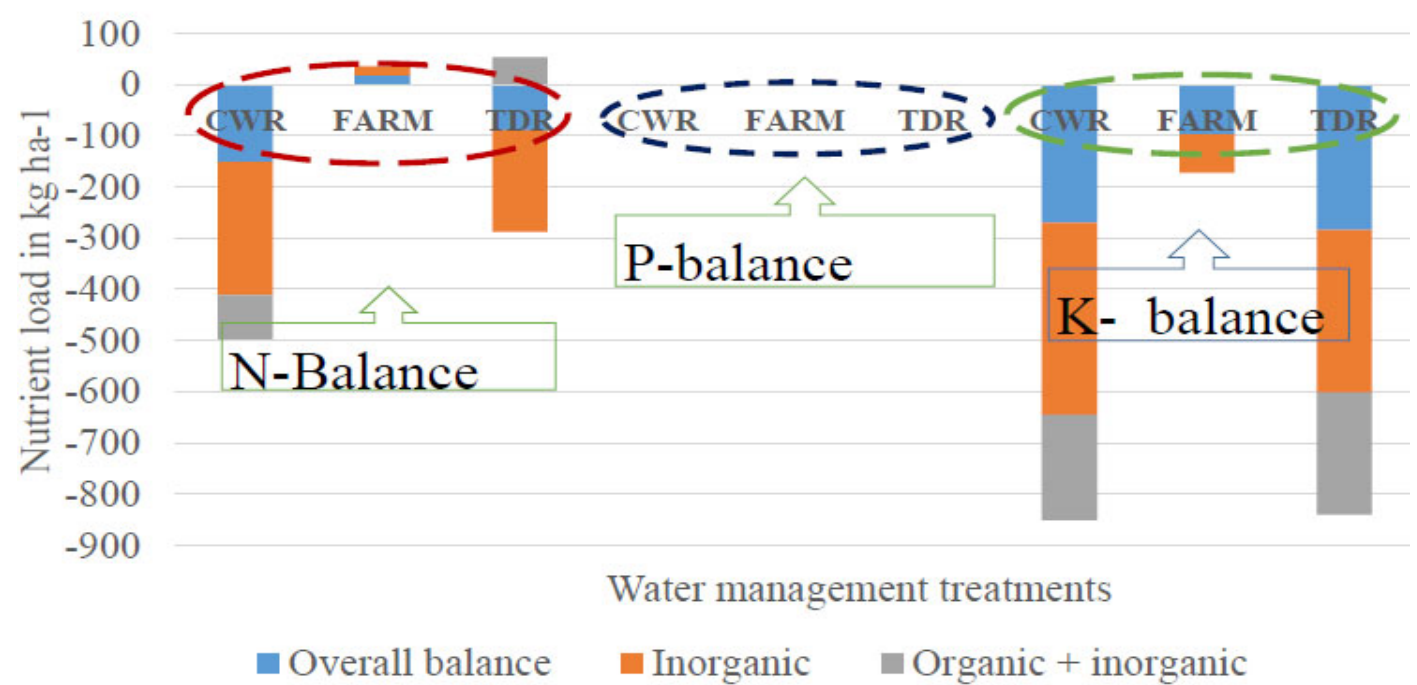

Figure 3.6: Partial depletion balance for mineral and manure fertilizer users

\section{Conclusion and Recommendation}

\subsection{Conclusions}

Climate based as well as the soil moisture based scheduling improved crop yield but did neither increase nor decrease the amount of water used. Results indicate that the farmers apply approximately the right amount of water but potentially not at the right time.

Farmers following one of the two irrigation scheduling methods did benefited from the water management in terms of yield. On average 37\% and 34\% more yield was obtained through CWR and TDR methods, respectively compared to the farmer's local practice. This illustrated the importance of the right amount of water at the right time which translated in sufficient nutrient up take resulting in higher yield.

\subsection{Recommendation}

To improve yield on smallholder farmers plots irrigation scheduling is not sufficient, nutrient scheduling is equally important. Good combination of both inorganic and organic fertilizer is needed to compensate for the increased nutrient removal by additional cropping seasons. Further research on full nutrient balance should be done to incorporate all fluxes. For example, leaching

\section{Reference}

ALI, M. \& TALUKDER, M. 2008. Increasing water productivity in crop production-a synthesis. Agricultural water management, 95, 1201-1213.

AWULACHEW, S. B., MERREY, D., VAN KOPPEN, B., KAMARA, A., PENNING DE VRIES, F. \& BOELEE, E. Roles, constraints and opportunities of small scale irrigation and water harvesting in Ethiopian agricultural development: Assessment of existing situation. International Water Management Institute Conference Papers, 2005.

GEBRESELASSIE, S. 2003. Helping small farmers to commercialize: Evidence from growing onion and tomatoes for sale in central Ethiopia. A Research Update of the Future Agricultures Consortium.

HORDOFA, T., MENKIR, M., AWULACHEW, S. B. \& ERKOSSA, T. 2008. Irrigation and rain-fed crop production system in Ethiopia.

TALUKDER, M. 2008. Increasing water productivity in crop production - a synthesis. Agricultural water management, 95, 1201-1213.

WHEATER, H. \& EVANS, E. 2009. Land use, water management and future flood risk. Land Use Policy, 26, S251-S264. 